\title{
The Role of Opinion Leaders in the Diffusion of New Knowledge: The Case of Integrated Pest Management
}

\author{
GERSHON FEDER and SARA SAVASTANO * \\ Development Research Group, The World Bank, USA
}

\begin{abstract}
Summary. - The paper reviews the literature on the characteristics and impact of opinion leaders on the diffusion of new knowledge, concluding that there is no clear evidence on whether opinion leaders are more effective if they are similar in socio-economic attributes to the other farmers rather than superior to would-be followers. A multivariate analysis of the changes in integrated pest management knowledge in Indonesia among follower farmers over the period 1991-98 indicates that opinion leaders who are superior to followers, but not excessively so, are more effective in transmitting knowledge. Excessive socio-economic distance is shown to reduce the effectiveness of diffusion. The paper then derives operational implications of the empirical results.

(C) 2006 Elsevier Ltd. All rights reserved.
\end{abstract}

Key words — Asia, Indonesia, opinion leaders, diffusion, innovations

\section{INTRODUCTION}

The subject of the diffusion of innovations received much attention in a variety of professional disciplines over the past few decades: Sociologists, economists, communications specialists, and education researchers proposed various theories on the factors and processes which underpin the observed patterns of information diffusion and the adoption of innovations (Rogers, 1995; Sunding \& Zilberman, 2001). The interest in this topic stems from the importance of innovative technologies, organizations, and contractual arrangements in improving the well being of societies and the environment. A better understanding of the processes by which new knowledge diffuses within and across societies and communities can suggest actions and investments that can be undertaken by governments and firms that aim to promote innovations. The large volume of empirical evidence that accumulated over the years clarified many aspects of diffusion processes and their characteristics in various contexts.

One key observation highlighted in many studies is the role of social links and community structure in the diffusion process. Communications and information relating to new knowledge were shown to be embedded within the more general fabric of social interactions among individuals. The pattern of information flows received and transmitted by individuals is thus related to their social environment, the network of their contacts, and their status within that network (see the literature cited in Brock \& Durlauf, 2001; Rogers, 1995). Recent empirical works by economists focused on a more precise definition of the social and communication networks of individuals whose technology decisions were analyzed (e.g., Bandiera \& Rasul, 2003; Conley \& Udry, 2003). The purpose of the present paper is to provide insights on

\footnotetext{
* Gershon Feder and Sara Savastano are, respectively, Research Manager and consultant, Development Research Group, The World Bank. The views expressed in this paper are those of the authors only, and do not necessarily represent the World Bank and its affiliated organizations. The first author had supervisory authority, on the World Bank's behalf, over the implementation of the IPM training project in Indonesia in the years 1995-97. Final revision accepted: December 8, 2005.
} 
an issue that is still not fully resolved in the empirical innovation diffusion literature, namely, the extent to which the attributes that make opinion leaders stand out in a community (social status, wealth, skills) can hamper or enhance their ability to disseminate information to an audience that is of a lesser status, lesser wealth, and lesser skills. The analysis utilizes data describing changes in knowledge regarding integrated pest management (IPM) among farmers in three provinces of Java, Indonesia, to demonstrate that leadership properties actually help in the diffusion of knowledge, but as the social and wealth disparity between leaders and would-be followers increases, the ability to disseminate knowledge diminishes at the margin, and may in fact decline.

The program of the paper is as follows: The next section reviews the relevant literature and derives the conceptual framework underpinning the empirical work in the paper. This is followed by descriptions of the promotion of IPM in Indonesia, and the data. A subsequent section outlines the analytical methodology followed by the empirical analysis. The last section provides conclusions and implications.

\section{LITERATURE REVIEW AND CONCEPTUAL FRAMEWORK}

The seminal work of Rogers (1995) provides a coherent theory, as well as empirical evidence, of many aspects of innovations diffusion. One of the themes elaborated upon is the role and characteristics of "opinion leaders." Such individuals have the status, expertise, links to external sources of knowledge, or experience that enable them to provide information and advice about innovations to others within their community. Opinion leadership is thus reflected in the ability to influence others' attitudes and knowledge (Chatman, 1987; Valente \& Davis, 1999). Such leadership may be informal rather than formal, but many scholars observed that opinion leaders tend to have higher social status than "followers" (Bandura, 1986, p. 151). Researchers also noted that opinion leaders are often more exposed to external sources of information, such as mass media or change agents (e.g., extension workers), have higher formal education, higher levels of literacy, a more cosmopolitan orientation, and higher income and wealth (Chatman, 1987; Rogers, 1995, p. 92; Valente, 1996; Weimann, 1994, p. 217).
The notion that opinion leaders, who stand out within the community in terms of their socio-economic and human capital characteristics, are key to information diffusion contrasts with the common observation (verified empirically) that most people tend to have communication networks composed mostly of individuals who are like them in social status and other respects. Sociologists and communications scholars define the tendency for communications to flow mostly among similar individuals as homophily, which is contrasted with heterophily, whereby individuals communicate with those who are different from them. The prevalence of homophily in communication networks leads to an alternative characterization of opinion leaders as being similar in their socio-economic characteristics to the followers. Thus, Weimann's (1994) comprehensive study of opinion leadership concludes that

\footnotetext{
"The almost single possible generalization on the socio-demographic level is the tendency towards similarity of the influential-influencee dyad. The trickledown model, suggesting a vertical flow from upper classes to lower classes, from more educated to less educated, or from higher income groups to lower income groups, was rejected in almost all domains. The more frequent flow was from leader to follower from the same social group. This tendency resulted in a homogeneity of the leader-followers groups in terms of most socio-demographic measures. People turn to seek advice from their peers, from individuals of the same background, interests, and values. The flow of information and influence is likely to be rather horizontal." (p. 88)
}

Rogers (1995) offers a possible middle ground between the two views. He observes that homophily may act as a barrier to the diffusion of new knowledge because "new ideas usually enter a system through higher status and more innovative members" (Rogers, 1995 , p. 288). But while he identifies a general tendency for followers to seek information and advice from opinion leaders who are perceived as more technically competent than themselves, he emphasizes that those leaders are selected so that they are not too much better. Thus, according to Rogers (1995, p. 294), "a follower typically seeks an opinion leader of somewhat higher status." Similarly, Valente and Davis (1999, p. 59) argue that "learning occurs most efficiently when individuals are trained by their "near peers," whom they have chosen as their models." These views reflect the notion of "optimal heterophily" (Alpert \& Anderson, 1973; Rogers \& Shoemaker, 1971), 
implying that excessive similarity, or excessive differences among individuals, could hinder the effectiveness of communication flows between them.

The measurement of capacity for opinion leadership attracted considerable attention in the literature. Early work by Rogers and Cartano (1962) describes three approaches: (i) the sociometric approach, whereby many members of a group are asked to identify those whose opinions are influential; (ii) a key informant approach, whereby a selected small group of individuals who are perceived as knowledgeable about the community are asked to identify the group's opinion leaders; (iii) the self-designating approach, where respondents are asked questions to determine the degree to which they perceive themselves to be opinion leaders. More complex approaches labeled as "network analysis" were developed in subsequent years, relying on formal methods for measuring who talks to whom in a community (Valente \& Davis, 1999; Valente \& Foreman, 1998). All these approaches allow a score-based continuous index of leadership, but require access to respondents who can be interviewed directly on matters of opinion leadership, provide information on the groupings and channels of communications, and serve as a basis for counts of the number of "nominations" a presumed opinion leader received from community members.

The empirical evidence on the impact of opinion leaders' socio-economic traits, as compared to the traits of other community members, on their effectiveness in diffusing information is not conclusive. For example, several studies highlight difficulties in the flow of information from higher status rural groups to lower strata (e.g., Roling, Ascroft, \& Wa Chege, 1976; Van de Fliert, 1993). Similarly, Weimann (1994) cites studies indicating that opinion leaders are similar in socio-demographic characteristics to followers. Yet the study by Gibbons, de Koninck, and Hasan (1980) documents the effective role of prominent and wealthier leaders as sources of information about innovations in rural settings. Sen (1969, p. 26) notes that "the direction of influence from leaders to followers is then vertical, from high to low strata of the village society." Similarly, Bose and Saxena (1966) found that rural opinion leaders, who were identified by other farmers as the most important source for agricultural information, were more literate, more competent, and superior in socio-economic standing.
For the purposes of framing the analysis in this paper, we formulate, based on the discussion in the literature, three alternative propositions that can be tested empirically:

(a) People are more likely to seek and acquire information from those who are similar to them in various socio-economic respects.

(b) People are more likely to seek and acquire information from those who have a higher status as opinion leaders, and who are thus superior to them in socio-economic attributes.

A third proposition reflects the "optimal heterophily" concept and its implication that effective opinion leaders will tend to be superior to others, but within bounds.

(c) People are more likely to learn from opinion leaders who are superior to them in socio-economic aspects, but who are not too different.

These propositions will be tested using data pertaining to the introduction of IPM knowledge in Indonesia through an intensive training program to selected farmers. As will be argued, these farmers were typically selected for their opinion leadership status or potential. Analyzing the extent to which other farmers' knowledge of IPM relates to the opinion leaders (who received intensive IPM training) in their communities will allow insights on the veracity of the three propositions.

\section{THE INTRODUCTION OF IPM KNOWLEDGE IN INDONESIA}

IPM in agriculture is an ecologically based approach to pest management. It aims to minimize the use of chemical pesticide by enhancing the abilities of natural enemies of pests, the crop itself, and various factors in the field environment, to control pests presence and reduce the loss that they can cause. IPM was introduced intensively in 1985 following a severe outbreak of pests in rice (a key strategic commodity in a country where rice is the staple food). The pest problem was traced to excessive use of chemical pesticides, which destroy pests and their predators alike, but following which certain pests can reemerge in much larger numbers in the absence of natural enemies. Following the government's acceptance of IPM as a desirable objective, training to farmers in IPM concepts was introduced in the 1990s through a large scale and intensive training program for farmers called the "Farmer Field School" 
(FFS) that was first piloted in 1989. This program utilizes participatory methods "to help farmers develop their analytical skills, critical thinking, and creativity, and help them learn to make better decisions" (Kenmore, 1997).

The typical FFS enhances participating farmer's knowledge on agroecosystems dynamics, within a framework of integrated pest and crop management. A great emphasis of the program has been on sensible pest management, safety with regard to chemical pesticides, and understanding of the interactions between pest insects and beneficial insects that limit the numbers and the impact of pests. With the knowledge gained in the FFS training, it was expected that a lower and safer use of chemical pesticides would be practiced by farmers.

Participatory training and hands-on experimentation are a key principle of the FFS, and the purpose of the training is to make the graduates "confident pest experts, self-teaching experimenters, and effective trainers of other farmers" (Wiebers, 1993). The group of trainees includes 20-25 participants from the village. The duration of an FFS is about 12-14 weeks within a full crop-growing season. A facilitator trainer leads the program, conveying knowledge on, and facilitating discussion of, ecologically based approaches in pest management, and overall good crop management decision procedures and practices. The training aims not only to sharpen the participants' decisionmaking abilities, but also to empower them for leadership and community activism (Scarborough, Killough, Johnson, \& Farrington, 1997, p. 102).

The selection of farmers for FFS training was not random, and sought to purposely include those with agricultural expertise, as well as others with high social status such as rich farmers and religious leaders (Winarto, 1994, p. 153). A detailed study from the early 1990s points out that those selected tended to be more affluent farmers, better educated and informed, who enjoyed higher status in the community. A relatively significant proportion of these selected farmers served also as official and semi-official village leaders (Van de Fliert, 1993, pp. 130 132). In fact, presumed or proven ability to spread information was a specific selection consideration at the local level, where selection was done by farmer group leaders in consultation with extension workers and village officials (Scarborough et al., 1997, p. 105; Van de Fliert, 1993, p. 203). Of course, there were situations where relatively young, lower status farmers were selected, although they needed to be perceived by the organizers of the training as being of high farming expertise (Winarto, 1994, 2004).

The cultural context certainly has an impact on the direction of communication flows and the perception of opinion leadership. The Javanese farming communities in the study areas are all Moslem, and tend to be hierarchical, and male dominated, with respect typically accorded to older and wealthier men, particularly if they achieved religious merit through pilgrimage to Mecca. ${ }^{1}$ While the donor-funded program attempted to purposefully select a larger number of women than would otherwise be proposed by local officials and village leaders, the actual proportion of women trained was rather small, and in many cases nonfarming women were included in the training simply to satisfy gender targets (World Bank Implementation Completion Report, 2000, p. 5). As there are no women in the sample, the study pertains to diffusion of knowledge among men only.

\section{DATA}

The data underlying this study were obtained through a panel survey of Javanese farm households conducted by the Indonesian Center for Agrosocio-economic Research (CASER) in April/May 1991 and again in June 1999. The baseline sample included rice-growing villages that had already been covered by the program, as well as villages that were not yet covered by the program, but were in areas where the program was planned to be implemented. All villages were visited in the repeat survey in 1999, but our analysis focuses only on those villages that had not yet been exposed to an FFS at the time of the baseline survey in 1991. In most of these villages, the village sample contains randomly selected farmers who participated in the training in various years throughout the period covered, as well as farmers from the same village who did not participate. Of the 268 sample households from the 22 sample villages where a field school had been implemented during 1991-99, only 112 had actually participated in the training while the remaining 156 households had not attended a program, but had been potentially exposed to some of its (new knowledge) benefits through informal communications and joint activities with graduates of the program who lived in their village. 
The 1991 survey collected information on households' farm operations and characteristics for the 1990-91 wet rice season and on their household attributes, activities, and assets. It also documented the farmers' knowledge of specific aspects of pest management that were to be included in the training program, through a set of questions on specific curriculum components. The 1999 survey repeated the same questions and collected additional data regarding the household and the village participation in FFS training, and more information about the community. The farmers' responses to the identical knowledge questions in both 1991 and 1999 were scored, and the number of correct answers relative to the total number of pest management questions serves as an indicator of pest management knowledge. ${ }^{2}$ More detailed information on the construction of the knowledge score is provided in Appendix A.

\section{ANALYTICAL METHODOLOGY}

The data do not contain information on the specific communication patterns, self-perceptions on leadership status, or numbers of nominations from peers received by farmers selected for training. It is thus not feasible to develop measures of opinion leadership for these farmers along the lines of work by Chatman (1987) or Valente and Davis (1999). However, it is possible to rely on the fact that the selection of farmers by program officers and village leaders to participate in the intensive IPM training was related to their observed or presumed opinion leadership potential, and on the availability of a number of socio-economic indicators related to opinion leadership for every farmer in the sample. In support of this approach, it is noted that studies of FFS training programs indicated that trained farmers were expected to proactively disseminate the knowledge gained in the course of the training to other members of the community (Scarborough et al., 1997, p. 105; Simpson \& Owens, 2002; Van de Fliert, 1993; Winarto, 1994). Obviously, not all potentially strong opinion leaders were selected for training. Similarly, some people with low opinion leadership capacity were included in the training in some villages. But it is reasonable to expect that persons with higher opinion leadership capacity had a higher probability of being selected for training. While the capacity for opinion leadership is not observable to the researcher, the literature suggests that such capacity is related to observed or measurable characteristics of the farmers, such as education, pre-training pest management knowledge, and wealth. One can thus utilize a dichotomous choice model such as probit to estimate, based on a sample of program-trained and untrained farmers, the parameters associated with observable indicators associated with opinion leadership:

$P=f\left(\beta^{\prime} X\right)$,

where $P$ is the probability of being selected, $X$ is a vector of observed leadership characteristics, and $\beta$ is a vector of parameters. The imputed value of the probability of selection $[\widehat{P}=$ $f\left(\hat{\beta}^{\prime}, X\right)$ where $\hat{\beta}$ is an estimate of $\left.\beta\right]$ can be viewed as an index of opinion leadership capacity, as it reflects this unobserved (to the researcher) capacity. This index can be calculated for every farmer in the sample, whether actually selected or not, once the parameter vector $\beta$ is estimated.

Because the data contain for each community in the sample several randomly selected trained farmers, these selected farmers may be viewed as a representative sample of the group of trained farmers in the specific village community. The average imputed index of opinion leadership capacity of the trained (selected) farmers of a given village (say, $\widehat{P}_{j}$ ) is an indicator of the extent of the IPM-trained opinion leadership available to disseminate the knowledge gained in the training in that village.

The difference in the imputed probability of selection of any two farmers is a measure of how different these farmers are in terms of their capacity for opinion leadership. A farmer with a lower probability is more likely to be a follower, compared with a farmer who has a higher probability. The ability to calculate the difference in capacities for opinion leadership provides us with a means for clarifying the effects of Rogers' concepts of homophily and heterophily on the communication of new knowledge between trained farmers and untrained farmers. If farmers tend to learn more from those better than themselves (i.e., from those who have a higher capacity for opinion leadership than themselves), then measurable changes in knowledge about IPM among farmers who did not attend the training will be positively related to the differences in capacities for opinion leadership (as represented by differences in the imputed probabilities for selection for training) between themselves and those 
who actually did attend the training. Given that in each community several farmers attended the training, the relevant reference in a given village $j$ is the average capacity for opinion leadership among the trained farmers in that village, as represented by $\widehat{P}_{j}$. That is, for any farmer $i$ (in village $j$ ) who did not attend training, the degree of similarity (homophily) with the trained group (denoted by $D_{i j}$ ) is approximated as

$D_{i j}=\widehat{P} j-f\left(\hat{\beta}^{\prime} X_{i j}\right)$,

where $f\left(\hat{\beta}^{\prime} X_{i j}\right)$ is the imputed probability of selection of untrained farmer $i$ in village $j$. If $D_{i j}$ is very close to zero, then the untrained farmer $i$ of village $j$ is very similar to the trained group from that village in the attributes that reflect capacity for opinion leadership. If $D_{i j}$ is positive, then the group of trained farmers of village $j$ is "better" (has on average a higher capacity for opinion leadership) than the untrained farmer $i$ of the same village.

Using the variable $D_{i j}$ as a measure of dissimilarity (socio-economic "distance") between the untrained farmers and the trained farmers in their villages enables the testing of the three alternative hypotheses formulated in Section 2: If untrained farmers are more likely to seek and learn IPM knowledge from opinion leaders who are similar to them (hypothesis (a)), then the gains in IPM knowledge by any farmer $i$ from village $j$ during the period 1991-98 covered by the two surveys will be negatively related to the absolute value of $D_{i j}$ (or to transformations of $D_{i j}$ which increase in value; the larger is the absolute value of $D_{i j}$, such as the square of $D_{i j}$ ). If untrained farmers are more likely to seek advice and learn from farmers who have strong opinion leadership characteristics and who are of higher socio-economic standing (hypothesis (b)), then the gains in untrained farmers' IPM knowledge during 1991-98 would be positively related to $D_{i j}$. If untrained farmers tend to learn from opinion leaders who are better than themselves, but not too much better (hypothesis (c)), then the relationship between gains in IPM knowledge and $D_{i j}$ will follow a nonlinear pattern such as a quadratic, where the linear term is positive, but the square term is negative (implying that at the margin, as the opinion leaders become too dissimilar to the followers, their impact on knowledge diffusion diminishes). Because hypothesis (b) is nested within hypothesis (c), the empirical formulation will test both hypotheses simultaneously.
More formally, if we denote the level of IPM knowledge in 1991 and 1999 as $K(0)$ and $K(1)$, respectively, then the following multivariate equations will facilitate the testing of hypothesis:

$$
K_{i j}(1)-K_{i j}(0)=\alpha+\gamma\left|D_{i j}\right|+\delta^{\prime} Z_{i j}+\mu^{\prime} V_{j+} \varepsilon_{i j},
$$

$$
K_{i j}(1)-K_{i j}(0)=\alpha+\gamma D_{i j}+\eta D_{i j}^{2}+\delta^{\prime} Z_{i j}+\mu^{\prime} V_{j+} \varepsilon_{i j},
$$

where $Z_{i j}$ is a vector of characteristics of untrained farmer $i$ from village $j$ which may affect knowledge acquisition aside from interactions with the trained farmers, and $V_{j}$ is a vector of village characteristics which can affect changes in knowledge of residents of that village. The parameter $\alpha$ is a constant, while the parameters $\lambda, \eta, \delta$, and $\mu$ are associated with the various explanatory variables. The term $\varepsilon_{i j}$ is a stochastic error. Eqn. (3a) is associated with hypothesis (a), while Eqn. (3b) is associated with hypotheses (b) and (c).

\section{EMPIRICAL SPECIFICATION AND ANALYSIS}

\section{(a) Factors affecting the selection of participants in IPM training}

The parameters of Eqn. (1) can be estimated as a probit, where, while the probability of selection is not observed, we define a dummy variable taking the value 1 when the data pertain to a farmer selected for training, and zero otherwise. The variables comprising the vector $X$ are suggested by the literature cited in Section 2, and include the following:

(i) Total rice land owned in 1991: The area of land owned is an indicator of wealth, and is related to status. Therefore, this indicator is expected to increase the probability of selection for training.

(ii) Area of unirrigated rice land owned in 1991: While holding total area owned constant, larger amounts of unirrigated land are negatively related to wealth and status and, therefore, will affect negatively the probability of selection.

(iii) Spending on pesticide per hectare of rice in 1991 (measured in natural logarithm): The volume of spending on pesticides is related to wealth, as well as to the potential interest 
in IPM. The probability of selection is, therefore, expected to be positively related to this indicator.

(iv) Number of household members in 1991: Larger households imply lower land per person (holding land area constant), and thus less wealth per capita, and lower status. It is, therefore, expected that household size will be negatively related to the probability of selection for training.

(v) Rice yield per hectare in 1991 (measured in natural logarithm): The yield is taken as an indicator related to farming skills. Higher yields are, therefore, expected to contribute positively to the probability of selection.

(vi) Education of household head in 1991: Farmers' education has been shown to positively affect their productivity (Jamison \& Lau, 1982) and is, therefore, another indicator of farming skills and status affecting the probability of selection positively.

(vii) Highest education level in the household in 1991: Families with more highly educated members are typically of higher status even if the selected farmer himself is not the most educated in the household.

(viii) Score on knowledge of IPM in 1991: The level of familiarity with IPM concepts is an indicator of a farmer's knowledge and skill in farming, and it is hypothesized to affect the probability of selection positively.

Because all variables reflected values in 1991, prior to the actual training (which took place in the 7 years after 1991), there is no endogeneity in the values observed. The means and standard deviations of the variables used in the analysis of the probability of selection are displayed in Table 1.

While the means of the two groups are not statistically different due to large standard er- rors, the data suggest that farmers selected for training tended to be larger landowners, with more irrigated land, higher spending on pesticides, higher yields, from families with more formal education, and better initial knowledge of IPM. These characteristics are all consistent with the profile of opinion leaders who are wealthier, better educated, and more skilled in farming. The probit analysis results presented in Table 2 essentially confirm these observations.

All variables have the expected sign and all, except for household size and farmer education, are statistically significant at least at the $10 \%$ level. About two-thirds of the observations would be correctly predicted using the estimated parameters (i.e., the sum of the percentage of trained farmers with imputed probability higher than $50 \%$, and untrained farmers with imputed probability of less than $50 \%$ ).

The parameters presented in Table 2 were used to impute the probabilities of selection for each farmer in the sample. An important issue is whether the factors affecting the selection of farmers into the training program have changed over time, in light of the observations on difficulties in horizontal communications made by early observers such as Van de Fliert (1993).

To examine this hypothesis, the sample of trained farmers was subdivided into two groups: (i) early trained (those who were trained prior to the initiation of the large-scale World-Bank-funded program in 1994), and (ii) those who were trained later, starting in 1994 (there were 57 and 55 farmers, respectively, in the two groups). A probit analysis was applied to the sample of 112 trained farmers, in which those selected later received the value 1 , while those selected early received the value zero. The explanatory variables were those used in

Table 1. Variables used in the analysis of the probability of selection for IPM training ${ }^{\mathrm{a}}$

\begin{tabular}{lccc}
\hline Variable & Unit & Untrained farmers & Trained farmers \\
\hline Sample size & persons & 156 & 112 \\
Total rice land (1991) & ha & .60 & .93 \\
Unirrigated rice area (1991) & ha & .19 & .07 \\
Spending on pesticides & 000 Rp/ha & 93 & 111 \\
Size of household & persons & 4.7 & 4.7 \\
Rice yield & kg/ha & 5757 & 6116 \\
Education of farmer & years & 5.1 & 5.7 \\
Highest education in family & years & 7.9 & 9.0 \\
Score on IPM knowledge in 1991 & $1-6$ & 2.52 & 2.65 \\
\hline
\end{tabular}

${ }^{a}$ Training took place after 1991. 
Table 2. Probit analysis of factors affecting selection of IPM training

\begin{tabular}{lc}
\hline Variable (1991 values) & Estimated parameter $^{\mathrm{a}}$ \\
\hline Total rice land (ha) & $.112^{*}(1.93)$ \\
Unirrigated rice land (ha) & $-1.054^{* * *}(2.60)$ \\
Spending on pesticides & $.087^{*}(1.77)$ \\
$\quad(1998$ '000 Rp/ha) & \\
Size of household (persons) & $-.067(1.27)$ \\
Rice yield (kg/ha) & $.884^{* *}(2.19)$ \\
Education of farmer (years) & $.040(1.51)$ \\
Highest education & $.081^{* *}(2.15)$ \\
$\quad$ in family (years) & $.196^{*}(1.71)$ \\
Score on IPM & \\
knowledge (integer 1-6) & $-9.232^{* * *}(2.64)$ \\
Constant & 268 \\
Sample size & $66 \%$ \\
\% Predicted correctly & .11 \\
Pseudo- $R^{2}$ & -162.99 \\
Log. likelihood & \\
\hline
\end{tabular}

${ }^{\text {a }}$ Numbers in parentheses are $Z$ values. Standard errors were corrected for clustering in villages.

* Significant at $10 \%$.

${ }_{* * *}^{* *}$ Significant at $5 \%$.

*** Significant at $1 \%$.

Table 2. None of the explanatory variables (nor the constant term) had statistically significant coefficients, implying that there is no significant difference in the actual selection criteria for the program between the earlier and later years.

These probabilities serve as indicators of farmers' opinion leadership capacity. For each village, the imputed probabilities for the subsample of trained farmers were summed up and divided by the number of trained farmers, yielding an estimate of the average opinion leadership capacity of IPM-trained farmers in that village $\left(\widehat{P}_{j}\right) .{ }^{3}$ Because in four villages the sample included only untrained farmers (no trained farmers from these villages were interviewed, although the training program was implemented in these villages), the subsample of untrained farmers from villages for which there was an estimate of $\widehat{P}_{j}$ was reduced to 117. For each one of these 117 farmers, the value of $D_{i j}$ was calculated following Eqn. (2). As explained in Section 5, the $D_{i j}$ values represent the extent of difference between the opinion leadership profile of the 117 untrained farmers and the average opinion leadership profile of the selected farmers from the same village who actually received intensive IPM training. The trained farmers could potentially serve as nodes of knowledge diffusion to the untrained farmers.

\section{(b) Analysis of the role of opinion leadership in IPM knowledge diffusion}

The diffusion of knowledge about IPM can be inferred by comparing the scores on IPM-related questions in 1991, before the implementation of the training program, and in 1999. By that time, the training program had already been administered to selected farmers in the villages covered under the present study, and the knowledge that the trained farmers gained was expected to diffuse to their neighbors and friends. The data indicate that the mean knowledge score of the 117 nonparticipants increased only slightly during $1991-99$ from 2.59 to 2.72 . This figure masks a considerable degree of variation, and further analysis can clarify the role of opinion leadership in the different villages in explaining the variation. However, farmers have various sources of information, and the analysis needs to account for variation among farmers in terms of their exposure to alternative sources of information, as well as differences among them in the effort that they exert to proactively seek information (Feder \& Slade, 1984). To account for these differences, the analysis needs to include variables representing such differences, in addition to the variable $D_{i j}$, which represents the interaction between the untrained farmers and those who have received intensive training.

One set of farmer-specific attributes, which may be related to differences in inclination to search for knowledge, are the indicators used to characterize opinion leadership, as displayed in Table 1. These variables, which are related to wealth, farming skills and education, can be hypothesized to relate also to general proclivity to seek information, regardless of the implementation of the intensive IPM training in the village.

Additional sets of variables, which can characterize the access to other sources of information, are defined at the village (rather than individual) level. These include the following:

(i) The number of sales kiosks in the village (1991): Kiosks are points of informal interactions among farmers, where inputs and household goods are bought and information can be exchanged. A larger number of such gathering spots can increase the opportunities for information acquisition.

(ii) Whether there is an active agricultural cooperative in the village (1991): Cooperatives played a role in pesticide distribution, and their employees may have promoted 
the use of pesticides in contravention of IPM concepts (Van de Fliert, 1993, pp. 203, 233). On the other hand, the cooperative office is also a place where farmers meet and information is exchanged. The impact of this indicator on knowledge diffusion is, therefore, uncertain.

(iii) The change in travel time to subdistrict townships, 1991-99: Subdistrict townships are the local market centers where farmers buy and sell products, and where they are exposed to additional sources of information. The longer the travel time to the township, the larger the transaction cost of accessing the market, and the less frequent are the trips to the market. This indicator is, therefore, negatively related to information diffusion.

(iv) Change in availability of Pest Observers in the village: Pest Observers are officials of the Plant Protection Department, assigned to monitor pest attacks and coordinate responses. With the advent of the intensive IPM training program, the number of Pest Observers was increased, and their role as sources of IPM information was enhanced (in fact, many of them functioned also as trainers in Farmer Field Schools). By 1999, each of our sample villages reported the presence of such an Observer. The change in this presence compared to the situation in 1991 is expected to be positively related to the diffusion of IPM knowledge.

(v) Change in the extent of village irrigation: This variable is a proxy to village overall level of wealth, and hence it is also an indicator of other village infrastructure and access to mass media. It is expected, therefore, that this variable is positively related to the diffusion of knowledge.

In addition to these village level variables, the analysis includes dummy variables for the three Java provinces (one of which serves as reference) where study villages are located, to reflect any aggregate differences in infrastructure changes such as transportation and communication that could affect diffusion.

Three different specifications of Eqns. (3a) and $(3 b)$ are used in order to verify that the results are not dependent on arbitrary formulations. The first two specifications, two-sided tobit and ordered probit, are standard methods of analyzing dependent variables which are censored and discreet. The dependent variable in the ordered probit specification is a categorical variable where three possible outcomes are de- fined: (i) "no improvement in knowledge score;" (ii) "small improvement in knowledge score (one point);" and (iii) "large improvement in knowledge score (two or more points)." One additional specification utilizes a transformation of the knowledge data into a continuous variable, through a logistic specification. The transformation entails conversion of the knowledge scores (which are integers in the range 0-6) into fractions by dividing them into 6 (the maximum number of correct answers). Denoting this fraction by $k$, one can define the logarithm of the odds ratio $\ln [k]$ $(1-k)]$, which is a variable in the range $(-\infty, \infty)$. The higher the knowledge score, the larger the odds ratio. The difference in the logarithms of the odds ratio during 1991-99 is similarly in the range $(-\infty, \infty)$. If it is assumed that the logarithm of the odds ratio is dependent linearly on the set of explanatory variables defined above, the analysis can be carried out by means of ordinary least squares. ${ }^{4}$

Table 3 presents alternative estimates of Eqn. (3a), allowing a test of hypothesis (a). As is evident from the results, the parameter associated with the absolute difference between the opinion leadership capacity of the untrained farmers and that of the trained farmers is not significantly different from zero. Therefore, the results provide no support to the hypothesis that farmers tend to learn more from those who are very similar to them. Alternative estimates of Eqn. (3b), designed to test hypotheses (b) and (c), are presented in Table 4.

Both the OLS estimate of the difference in logarithms of odds ratio and the ordered probit estimate confirm hypothesis (c) that both the linear term and the quadratic term are statistically significant. ${ }^{5}$ The two-sided tobit estimate is similar in magnitude, except that the quadratic term is not significant even at a $10 \%$ level. However, while the standard errors for the ordered probit and the OLS estimate were corrected for clustering of observations at the village level, such a correction is not feasible in the tobit procedure. It is possible, however, that the estimates of the standard errors in the tobit equation are biased upwards in the absence of the clustering correction, as it is observed that most of the test statistics ( $z$ and $t$ ) in the other equations have higher values. The three alternative estimates yield a fairly similar critical value of $D_{i j}$ beyond which any additional superiority of the opinion leaders detracts from their communication effectiveness: such a critical value maximizes the terms 
Table 3. Test of the hypothesis that diffusion is faster if opinion leaders are similar to other farmers

\begin{tabular}{|c|c|c|c|}
\hline Variable $^{\mathrm{a}}$ & $\begin{array}{l}\text { Two-sided tobit } \\
\quad(N=117)\end{array}$ & $\begin{array}{l}\text { Ordered probit }{ }^{\mathrm{b}} \\
\quad(N=117)\end{array}$ & $\begin{array}{c}\text { OLS of log. odds ratio }{ }^{b} \\
(N=117)\end{array}$ \\
\hline $\begin{array}{l}\text { Absolute difference in opinion } \\
\text { leadership capacity }\left|D_{i j}\right|\end{array}$ & $-0.062(0.05)^{\mathrm{c}}$ & $0.377(0.52)^{\mathrm{d}}$ & $-0.058(0.08)^{\mathrm{c}}$ \\
\hline Total rice land (ha) & $-0.007(0.05)$ & $-0.006(0.04)$ & $-0.005(0.06)$ \\
\hline Unirrigated rice area (ha) & $-0.357(1.14)$ & $-0.335(0.75)$ & $-0.243(0.85)$ \\
\hline Spending on pesticides ('000 Rp/ha) & $-0.013(0.20)$ & $0.010(0.18)$ & $-0.008(0.16)$ \\
\hline Size of household (persons) & $0.111(1.59)$ & $0.103^{* *}(1.97)$ & $0.081^{*}(1.71)$ \\
\hline Rice yield (kg/ha) & $0.420(0.89)$ & $0.009(0.02)$ & $0.306(1.22)$ \\
\hline Education of the farmer (years) & $-0.012(0.25)$ & $0.049(0.91)$ & $-0.009(0.28)$ \\
\hline Highest years of education (years) & $0.016(0.35)$ & $0.031(0.75)$ & $0.018(0.70)$ \\
\hline No. of sale kiosks (numbers) & $0.482^{* * *}(2.87)$ & $0.274^{* *}(2.03)$ & $0.334^{* * *}(3.13)$ \\
\hline Cooperative (numbers) & $0.342(0.86)$ & $0.064(0.18)$ & $0.196(0.58)$ \\
\hline Change in travel time to town (time) & $-0.062^{* * *}(2.71)$ & $-0.040^{* *}(2.24)$ & $-0.046^{* * *}(3.81)$ \\
\hline Change in availability of pest observer (numbers) & $0.609^{*}(1.96)$ & $0.447^{*}(1.90)$ & $0.431^{* * *}(2.95)$ \\
\hline Change in village irrigation $(\%)$ & $-0.078(0.16)$ & $0.031(0.07)$ & $-0.019(0.07)$ \\
\hline Observations & 117 & 117 & 117 \\
\hline$R^{2} /$ pseudo- $R^{2}$ & 0.06 & 0.07 & 0.18 \\
\hline
\end{tabular}

${ }^{a}$ Regressions also include constant and dummy variables for province.

${ }^{\mathrm{b}}$ Standard errors adjusted for clustering at village level.

${ }^{c}$ Numbers in parentheses are $t$-statistics.

d Numbers in parentheses are $Z$-statistics.

* Significant at $10 \%$.

** Significant at 5\%.

${ }^{* * *}$ Significant at $1 \%$.

Table 4. Test of the hypothesis of diffusion through opinion leaders who are superior to the followers

\begin{tabular}{lccc}
\hline Variable $^{\mathrm{a}}$ & $\begin{array}{c}\text { Two-sided tobit } \\
(N=117)\end{array}$ & $\begin{array}{c}\text { Ordered probit }^{\mathrm{b}} \text { OLS of log. odds ratio } \\
(N=117)\end{array}$ & $\begin{array}{c}\text { O }^{\mathrm{b}} \\
(N 17)\end{array}$ \\
\hline Difference in opinion leadership capacity $\left(D_{i j}\right)$ & $4.788^{* * *}(4.28)^{\mathrm{c}}$ & $4.311^{* * *}(3.48)^{\mathrm{d}}$ & $3.503^{* * *}(4.51)^{\mathrm{c}}$ \\
Square of the difference in opinion & $-4.700(1.56)$ & $-4.998^{* *}(2.34)$ & $-3.492^{* *}(2.20)$ \\
$\quad$ leadership capacity $\left(D_{i j}^{2}\right)$ & & & \\
Total rice land (ha) & $0.145(1.02)$ & $0.116(0.97)$ & $0.106^{*}(2.00)$ \\
Unirrigated rice area (ha) & $-1.082^{* * *}(3.26)$ & $-0.907^{* *}(1.98)$ & $-0.773^{* *}(2.67)$ \\
Spending on pesticides ('000 Rp/ha) & $0.104(1.60)$ & $0.106^{*}(1.83)$ & $0.077(1.66)$ \\
Size of household (persons) & $-0.013(0.18)$ & $-0.002(0.04)$ & $-0.010(0.21)$ \\
Rice yield (kg/ha) & $1.523^{* * *}(3.03)$ & $0.925^{*}(1.93)$ & $1.113^{* * *}(3.72)$ \\
Education of the farmer (years) & $0.030(0.64)$ & $0.083(1.59)$ & $0.022(0.64)$ \\
Highest years of education (years) & $0.101^{* *}(2.13)$ & $0.102^{* *}(2.20)$ & $0.080^{* *}(2.72)$ \\
No. of sale kiosks (numbers) & $0.501^{* * *}(3.20)$ & $0.346^{* *}(2.22)$ & $0.348^{* * *}(3.78)$ \\
Cooperative (numbers) & $0.423(1.14)$ & $0.214(0.59)$ & $0.252(1.00)$ \\
Change in travel time to town (time) & $-0.057^{* * *}(2.66)$ & $-0.043^{* *}(2.07)$ & $-0.042^{* * *}(3.26)$ \\
Change in availability of pest observer (numbers) & $0.965^{* * *}(3.23)$ & $0.819^{* *}(2.47)$ & $0.691^{* * *}(3.77)$ \\
Change in village irrigation (\%) & $0.370(0.79)$ & $0.471(0.93)$ & $.308(0.81)$ \\
Observations & 117 & 117 & 117 \\
$R^{2} /$ Pseudo- $R^{2}$ & 0.11 & 0.11 & 0.29 \\
\hline
\end{tabular}

\footnotetext{
${ }^{a}$ Regressions also include constant and dummy variables for province.

${ }^{\mathrm{b}}$ Standard errors adjusted for clustering at village level.

${ }^{\mathrm{c}}$ Numbers in parentheses are $t$-statistics.

${ }^{d}$ Numbers in parentheses are $Z$-statistics.

* Significant at $10 \%$.

** Significant at 5\%.

*** Significant at $1 \%$.
} 
$\gamma D_{i j}+\eta D_{i j}^{2}$, and is calculated as the value of $D_{i j}$ where the first derivative of the latter term is zero. The parameter estimates of $\gamma$ and $\eta$ in Table 4 indicate that the critical value is in the range $.43-.50$, and thus when the leadership capacity index exceeds that range, the ability to diffuse information declines.

The estimation results for other factors contributing to knowledge diffusion are mostly as expected, and quite consistent regardless of the estimation specification. In particular, higher yield levels, larger irrigated areas, and higher education in the household are farmer characteristics significantly related to knowledge gains. Farmers located in villages with more sales kiosks, closer to market towns, and with increased presence of pest protection government officials were more likely to increase their knowledge of IPM, in part through access to alternative sources of information, that is facilitated by these characteristics.

\section{CONCLUSIONS AND IMPLICATIONS}

The results in the preceding section confirm that differences in the opinion leadership capacity of farmers who were trained intensively in IPM field schools explain, among other factors, the variation in IPM knowledge gains among farmers who did not participate directly in the training. The effectiveness of opinion leaders in diffusing knowledge that was specifically targeted to them through intensive training was shown to depend positively on the extent of leaders' superiority compared to the socioeconomic and farming skill attributes of the would-be followers. However, the results indicate that if the selected opinion leaders are excessively superior to the others in the community, their effectiveness actually diminishes and they may become essentially irrelevant to the diffusion of knowledge beyond a small circle of those higher status individuals who are closely associated with them.

These conclusions have implications for the operations of extension and information programs seeking to spread new knowledge widely across large populations, particularly in areas where mass media sources are not accessible to the majority of the population. Such programs have traditionally focused the direct interactions of change agents (extension work- ers, trainers) on selected individuals, as budget and manpower constraints would not allow for direct interaction with every member of the target population. For example, the Training and Visit extension program instructed extension agents to select permanent groups of "contact farmers" for their bi-weekly village visits (Benor \& Harrison, 1977). The Farmer Field School training approach focused similarly on selected groups of participants in intensive training. Several other knowledge enhancement programs described in Scarborough et al. (1997) followed similar selection and diffusion strategies.

As is evident from the results of the present analysis, it is possible to err in two opposite directions: (i) selecting diffusion agents who are too "average" to the point that they are not much respected as leaders, and (ii) selecting opinion leaders who are too prominent and atypical to the point that most members of the community do not interact with them, or view their knowledge as being likely irrelevant. Obviously there are circumstances where programs include representatives of the latter group for political reasons, but the analysis suggests that such representation should not be excessive. Similarly, there may be circumstances where lower-status members of the community who are not currently opinion leaders should be included for purposes of empowerment and development of their potential leadership capacity. In such cases, one needs to recognize that these are the main purposes of such individuals' inclusion, rather than the diffusion of knowledge.

Striking the right balance in the selection of program participants, as implied by the results of the present paper, is conceptually appealing, but not easy to implement in practice, as a combination of attributes (with unknown aggregation weights) is relevant, and some of the traits may not be readily observed by outsiders and researchers (although often known to members of the communities involved). Community participation in selecting those to be targeted for roles as opinion leaders can overcome some of the challenges (Valente \& Davis, 1999). It is likely that different types of programs may require different types of leaders (e.g., reflecting gender or ethnic aspects), and additional analysis is required to clarify the contextual factors that need to be considered. 


\section{NOTES}

1. A detailed description of the cultural aspects of communication flows in Indonesia, in the context of the IPM training program, is provided in Winarto (2004).

2. While the pest management questions asked (six in number) cover only part of the pest management training, they are viewed as a good indicator of the IPM knowledge gained in the course of training. This is confirmed by Feder, Murgai, and Quizon (2004) who reported an analysis of the relation between pest management knowledge scores in this dataset and the utilization of chemical pesticides by the farmers. Their results indicated that farmers with higher IPM knowledge scores utilized statistically significantly less pesticides, although the extent of the change was modest.
3. As explained in Appendix B, data limitations compel us to conduct the analysis at the village level, while the ideal case would focus on the hamlet (sub-village) level. This implies strong assumptions spelled out in Appendix B.

4. One can show that this formulation is consistent with a model whereby the knowledge score is related to the household and village characteristics through a logistic equation $K_{t} / 6=1 /\left[\mathrm{e}^{-\theta-\lambda^{\prime} Q}\right]$, where $\theta$ and $\lambda$ are parameters, and $Q$ is the vector of explanatory variables.

5. The possibility of time effects was checked by including an interaction term between the variable $D_{i j}$ and the length of time since training was provided in the village. The parameter of the interaction term was not statistically significant.

\section{REFERENCES}

Alpert, M., \& Anderson, T. (1973). Optimal heterophily and communication effectiveness: Some empirical findings. Journal of Communication, 23(3), 328343.

Bandiera, O., \& Rasul, I. (2003). Complementarities, social networks, and technology adoption in Mozambique. Unpublished manuscript, London School of Economics.

Bandura, A. (1986). Social foundations of thought and action. Englewood Cliffs, NJ: Prentice-Hall.

Benor, D., \& Harrison, J. (1977). Agricultural Extension: The Training and Visit System. Washington, DC: World Bank.

Brock, W., \& Durlauf, S. (2001). Interaction based Models. In J. Heckman, \& E. Leomer (Eds.). Handbook of econometrics (Vol. 5, pp. 3297-3380). Amsterdam: North Holland.

Bose, A. B., \& Saxena, P. C. (1966). Opinion leaders in a village in Western Rajasthan. Man in India, 46(2), 121-129.

Chatman, E. (1987). Opinion leadership, poverty, and information sharing. $R Q, 26(3), 341-353$.

Conley, T., \& Udry, C. (2003). Learning about new technology: Pineapple in Ghana. Unpublished Manuscript, Yale University.

Feder, G., \& Slade, R. (1984). The acquisition of information and the adoption of new technology. American Journal of Agricultural Economics, 66(3), 312-320.

Feder, G., Murgai, R., \& Quizon, J. (2004). The acquisition and diffusion of knowledge: The case of pest management training in farmer field schools, Indonesia. Journal of Agricultural Economics, 55(2), 217-239.

Gibbons, D., de Koninck, R., \& Hasan, I. (1980). Agricultural modernization, poverty and inequality:
The distributional impact of the green revolution in regions of Malaysia and Indonesia. Westmead, Farnborough: Teakfield LTD.

Jamison, D., \& Lau, L. (1982). Farmer education and farm efficiency. Baltimore, MD: Johns Hopkins University Press.

Kenmore, P. (1997). A perspective on IPM. Center for Information on Low External Input and Sustainable Agriculture, Newsletter, 13(4).

Rogers, E. (1995). Diffusion of innovations (4th ed.). New York, NY: The Free Press.

Rogers, E., \& Cartano, D. (1962). Methods of measuring opinion leadership. Public Opinion Quarterly, 26(4), 435-441.

Rogers, E., \& Shoemaker, F. (1971). Communication of innovations: A cross cultural approach. New York: The Free Press.

Roling, N., Ascroft, J., \& Wa Chege, F. (1976). Diffusion of innovations and the issue of equity in rural development. Communications Research, 3(2), 155-171.

Scarborough, V., Killough, S., Johnson, D., \& Farrington, J. (1997). Farmer-led extension: Concepts and practices. London: Intermediate Technology Publications.

Sen, L. K. (1969). Opinion leadership in India: A study of interpersonal communication in eight villages. Hyderabad: National Institute of Communication Development.

Simpson, B., \& Owens, M. (2002). Farmer field schools and the future of agricultural extension in Africa. Sustainable Development Dimensions, Food and Agriculture Organization, Rome.

Sunding, D., \& Zilberman, D. (2001). The agricultural innovation process: Research and technology adoption in changing agricultural sector. In B. Gardner, \& 
G. Rausser (Eds.). Handbook of agricultural economics (Vol. 1a, pp. 207-226). Amsterdam: North Holland.

Valente, T. (1996). Social network thresholds in the diffusion of innovations. Social Networks, 18(1), 69-89.

Valente, T., \& Davis, R. (1999). Accelerating the diffusion of innovations using opinion leaders. Annals of the American Academy of Political and Social Science, 566(1), 55-67.

Valente, T., \& Foreman, R. (1998). Integration and radiality: Measuring the extent of an individual's connectedness and reachability in a network. Social Networks, 20(1), 89-105.

Van de Fliert, E. (1993). Integrated pest management: Farmer field schools generate sustainable practices. A case study in Central Java evaluating IPM training (304 pp). Wageningen Agricultural University Paper No. 93-3. Wageningen, The Netherlands: PUDOC.

Weimann, G. (1994). The influentials. Albany, NY: State University of New York Press.

Wiebers, U. C. (1993). Integrated pest management and pesticide regulation in developing Asia. World Bank Technical Paper No. 211. Asia Technical Department Series, Washington, DC.

Winarto, Y. (1994). Encouraging knowledge exchange: Integrated pest management in Indonesia. In I. Scoones, \& J. Thomson (Eds.). Beyond farmers first: Rural people's knowledge, agricultural research, and extension practice (pp. 150-154). London: Intermediate Technology Publications.

Winarto, Y. (2004). Seeds of knowledge: The beginning of integrated pest management in Java. New Haven, CT: Yale Southeast Asia Studies, Monograph 53.

World Bank (2000). Implementation completion report for the Indonesia integrated pest management training project, June 2000 .

\section{APPENDIX A. CONSTRUCTION OF THE KNOWLEDGE VARIABLE}

The farmer interviews held in 1991 and in 1999 sought to establish farmers' familiarity with key elements of the pest management principles promoted in the FFS curriculum. The questions were not necessarily posed in a direct "Yes" or "No" format, and often involved some preliminary conversation on the topic and clarifications. After the farmer responded to themes brought up by the interviewer, the latter was in a position to judge whether the farmer was "knowledgeable" or not regarding the specific theme. The six themes that were the specific focus of the interview on pest management were: (i) Whether it is advisable to have a pre-set schedule of spraying against rice pests or to spray at the early stage of plant growth, if insects are observed or if insect damage is noticed. IPM principles suggest that preset spraying schedules, and spraying in reaction to pest or pest damage in the early phases are not useful.

(ii) Whether there are nonchemical measures (biological or mechanical) that can be utilized to minimize the presence of, or vulnerability to, pests. The training establishes a number of nonchemical alternatives.

(iii) Whether the respondent could identify correctly at least $70 \%$ of pests from a list of candidates.

(iv) Whether the respondent could identify at least $70 \%$ of beneficial insects and living organisms, which actually suppress pests.

(v) Whether the respondent is aware of the benefits of synchronized planting of crops so as to minimize the opportunities for pest damage and proliferation.

(vi) Whether the respondent is aware of the benefits of practicing crop rotations so as to minimize pest resurgence and proliferation.

The number of correct answers relative to the total (i.e., the proportion of correct responses) defines the score of knowledge for each farmer. Farmers with a higher knowledge score are expected to be less vulnerable to pest attacks or pest damage, and are likely to use less chemical pesticides.

\section{APPENDIX B. DATA LIMITATIONS OF THE ANALYSIS AT THE VILLAGE LEVEL}

In the Indonesian context, a distinction needs to be drawn between the term village (desa), which is an administrative unit, and hamlet (dusun), which is a social community. A desa typically contains several geographically proximate or adjacent dusuns. The sample was drawn from 22 villages containing 42 hamlets. In eight of the hamlets, the sample contained only untrained farmers, while in six hamlets the sample contained only trained farmers. Therefore, while the analysis of the selection of trained farmers pertains to all 22 villages and their 42 hamlets, the analysis of diffusion pertains to 17 villages (and their 29 hamlets) in which the sample contains both trained and untrained farmers. In four villages, there was 
only one hamlet each in the sample. The number of sampled trained farmers from any given hamlet is in most cases too small (sometimes only two or three) to form a unit of observation for the present paper's diffusion analysis, as the model requires the calculation of a mean leadership profile for each communication network. The hamlet is a much more cohesive, social, and communication network than the village, and ideally one would conduct the analysis at the hamlet level. The analysis in the present paper uses the village, rather than the hamlet, as the communication network frame, under the strong assumptions that the social structure in all the hamlets of one village is similar, and the selection process of opinion leaders for training was similar in these hamlets. Under such assumptions, the aggregated samples drawn randomly from the hamlets of a given village are unbiased representations of the social profiles of trained and untrained farmers, within each hamlet of that village, and the estimated average opinion leadership index at the village level represents the type of opinion leadership that an untrained farmer from a hamlet in that village was exposed to.

An analysis that utilized data at the hamlet level (omitting all hamlets where there were only three or less graduates or three or less untrained farmers) yielded results that were qualitatively similar, but because a smaller sample (only 84 untrained farmers compared to 117) could be utilized, the statistical significance of several of the variables was low, although the signs and the magnitudes of the key parameters were similar to that of the analysis at the village level, and the key result of the paper holds. That is, even with the smaller sample, the parameter of $D_{i j}$ in Table 4 is significant, although the parameter of the square of $D_{i j}$ is not significant $(t=1.51)$, but negative. 